\title{
A Study of English Phrase Verb in Language Learning
}

\author{
Yongchang Rong*
}

Shanghai Maritime University, Shanghai 201306, China

\begin{abstract}
A phrase verb is a combination of verbs and adverbs or a preposition word. The increase in the number and the extensive use of the phrase verb is a notable feature of modern English, which has caused the extensive attention of linguists. Research situation of domestic and International English phrasal verbs are summarized in this paper putting forward from the perspective of cognitive linguistics to teaching of English phrasal verbs which should go to particle center processing path and give learners to images showing the polysemy of phrasal verbs and particles. The method of semantic analysis of phrase verb is in line with the law of human's cognition, which can promote the acquisition of English phrase verbs by foreign language learners through the expansion of metaphor.
\end{abstract}

Keywords: English, language learners, phrase verb, research method.

\section{INTRODUCTION}

English phrasal verbs can be traced back the history of the Anglo Saxon period. Influenced by the Germanic, some verbs and adverbs prefix, such as be, for -, under-, over- and so on, constitute the compound verbs. Subsequently, due to the influence of foreign languages such as French and Latin, the adverbs have been increased, which can be independent of the adverbs and move to the verb, thus forming a phrase verb. As a term for English grammar, the phrase "Words Logan" (and Idioms) was first used in the phrase "Pearsall Smith". After that, there are many different forms of expression, such as the verb adverb or the verb and the preposition combination, the discontinuous verb, the compound verb, the verb, the verb, and so on.

The phrase verb has a strong combination, the number and the use of a wide range of features, while the semantic and grammatical structure of the complex, has been an easy to grasp of English learners. Because most of the phrase verbs have their fixed meaning, they cannot be inferred from the literal meaning of the whole phrase, which resulted in the difficulty of English learners. In order to help the learners is easy and efficient acquisition of English phrasal verbs. In this paper, the teaching methods of English phrasal verbs from the domestic and foreign scholars of, and the research methods of corpus linguistics, investigate how Chinese EFL learners of phrasal verb acquisition condition.

\section{STUDY ON THE METHOD OF FOREIGN ENG- LISH PHRASES}

The difficulty of learning the meaning of the phrase verb lies in the understanding of the meaning of the whole phrase and the choice of the word.

\subsection{Traditional Research Methods}

The traditional research on the phrase verb is mostly from the structural principle, which mainly focuses on its syntactic features [1]. This paper analyzes the surface structure of the sentence, and discusses the position of the words. Quark launched the comprehensive English grammar book "'is considered to represent the syntactic study of verbs. In the study of the quark et al, the phrase verb is called "multi word verb" ". Verb and adverb or a preposition or both constitutes the phrasal verbs, expressing a complete concept of indivisible, people when in use to treats as words in the true meaning of the word, and not a few words of any combination. That quark particles belong to two different but overlapping categories: Spatial Prepositions and adverbs. The essay is divided into three categories. Quark launched the "English grammar" comprehensive work is considered to be representative of the syntax of verb phrases. In the study of the quark et al, the phrase verb is called "multi word verb". Verbs and adverbs or prepositions or both of phrasal verbs, the expression of a complete concept of indivisible, verb and adverb or a preposition or both constitutes the phrasal verbs, a complete concept of integral expression, when people use it as word lexical treated and not a few words of any combination [2]. That quark particles belong to two different but overlapping categories: Spatial Prepositions and adverbs. The essay is divided into three categories.

It is only used as prepositions, such as: against, as, at, beside, for, from, into, like, among, of, onto, with, upon.

It is only used for spatial adverbs, such as: aback, ahead, back, forward, apart, front in, out (UK), together.

It can be used as a preposition and an adverb in space. In the spatial adverb, also known as prepositions and adverbs, such as: about, above, across, after, and along and around, by, down, in, off, out (American English), over, past, under, up. 
Table 2. Basic meaning of verb-extended meaning.

\begin{tabular}{|c|c|}
\hline Spatial Prototypical or Basic Meanings & Metaphrical of Ex-tended Meanings \\
\hline \hline a. Do you know there is some petrol leaking out of your tank? & b. In the middle age, epidemics wipe out \\
\hline a. The children ran up the hill to attack the emery & b. It is up to you to decide \\
\hline a. wipe the dirt off your face & b. His initial enthusiasm wore off fast \\
\hline
\end{tabular}

Table 3. The metaphorical extensions of into, out, on.

\begin{tabular}{|c|c|c|}
\hline & TR & LM \\
\hline \hline Peter got on the bus & Peter & The bus \\
\hline Mother sent the boy out to buy something to eat & The boy & mother \\
\hline After years of discipline, he turned into a manager & he & A manager \\
\hline
\end{tabular}

Table 4. The number of words of CLEC in each sub corpus.

\begin{tabular}{|c|c|c|c|c|c|c|}
\hline Type & ST2 & ST3 & ST4 & ST5 & ST6 & Total \\
\hline \hline The number of words & 208088 & 209043 & 212855 & 214510 & 226106 & 1070602 \\
\hline
\end{tabular}

Rudzka Ostyn used in cognitive linguistics container metaphor and emitter trajector and landmark 1andmark (hereinafter referred to as TR, LM) theory, which consults the words of the phrase verb, to express the cognitive processing of the brain (See Table 3).

It is necessary to explain the meaning of the phrase verb from a cognitive point of view, and the meaning of it is to be a visual representation of the meaning, which can promote the learning of the learners.

\section{THE STUDY OF THE DOMESTIC ENGLISH PHRASE VERB}

Since the 80's in twentieth Century, the domestic scholars have begun to study English phrases, such as Wang Rongpei, Lu Guo Qiang, Zhang Daozhen, etc. From the perspective of structuralism, they are more concerned about the two aspects: the stability of the structure and the syntactic function. In addition [7], more and more scholars began concern phrasal verb semantic structure, began to accept the view that phrasal verb semantic unity and structural stability: at the same time, they are also aware of the ambiguity characteristics of phrasal verbs. In recent years, the development of cognitive linguistics provides a new perspective for the study of the phrase verb. Wang Rongpei and Lu Xiaojuan (1997) used the Cowie classification method [8], that is, the phrase verb six points. They are regarded as the verb + noun, verb + noun, verb + adjective and verb + verb. They have carried out a systematic study of the meaning, composition and characteristics of the phrase verb, which suggests that the English learners should pay attention to the accumulation, especially in the conversation. Lu Guoqiang thinks that idioms in nature (verbal), there are 6 kinds of structure.

1) verb + short term (verb+particle) $\mathrm{a}$, verb + adverb; b, verb + preposition; c, verb + Adverb + preposition.

2) verb + noun: make the grade

3) verb + preposition phrase: beat about the bush

4) verb + noun + preposition phrase: burn the candle at both ends

5) verb + noun + preposition: get wind of

6) verb + adjective: go easy

Some scholars have made a tentative research on the teaching of English phrases. Quan Fu Li comprehensively discussed the characteristics of English phrasal verbs and put forward teachers to use synonymous with more familiar with the interpretation of the meanings of phrasal verbs to deepen the impression, using the antisense phrasal verbs and phrasal verbs to explain, by comparing the enhanced memory and of some frequently used or phrasal verbs, depending on the context judge its significance.

\section{A STUDY OF CHINESE LEARNERS' ACQUISI- TION OF ENGLISH CORPUS}

\subsection{Corpus and Retrieval Tools}

This research chose CLEC and LOCNESS corpus. CLEC include high school students (ST2), College English level 4 (ST3), College English level 6 (ST4), English professional 1 $\sim 2$ grade (ST5), learning English for $3 \sim 4$ grades (ST6) composition [9], the corpus distribution as shown in Table 4.

\subsection{The Range and Extraction Method of the Phrase Verb}

Liao and Zhang Bin's research are divided into two kinds of semantic transparency (transparent) and figurative. Se- 
Table 5. 72 phrase verbs are divided into two groups, which are semantic transparency and figurative meaning.

\begin{tabular}{|c|c|}
\hline Semantic Transparency(n=37) & Figurative Meaning(n=35) \\
\hline \hline $\begin{array}{c}\text { Bring down, Bring in, Bring out, Come around, Come back, Come down, } \\
\text { Come in, Come out, Come up, Find out, Get along, Get away, Get down, } \\
\text { Get off, Get on, Get out, Get through, Get up, Go ahead, Go down, Go off, } \\
\begin{array}{c}\text { Go out, Go up, Look up, Pick up, Point out, Put away, Put down, Put in, Put } \\
\text { on, Put up, Stand up, Take apart, Take back, Take down, Take off, Take out }\end{array}\end{array}$ & $\begin{array}{c}\text { Bring about, Bring on, Bring up, Carry out, Come about, Come across, } \\
\text { Come along, Come off, Come on, Get back at, Give up, Go about, Go } \\
\text { along, Go in, Go on, Go over, }\end{array}$ \\
$\begin{array}{c}\text { Set up, Take in, Take on, Take over, Take up, Turn down, Turn in, Turn on, } \\
\text { Turn out, Turn up }\end{array}$ \\
\hline
\end{tabular}

Table 6. The first 5-super phrase verbs.

\begin{tabular}{|c|c|c|c|c|}
\hline ST2 & ST3 & ST4 & ST5 & Come back \\
\hline \hline Go over & Go out & Take up & Go out & Set up \\
\hline Get up & Run out & Go in out & Get up & Give up \\
\hline Go out & Get up & Get up & Give up up \\
\hline Come back & Stand up & Get along & Look up & Bring about \\
\hline Make up & Get along & Find out &
\end{tabular}

Table 7. The first 5-little phrases.

\begin{tabular}{|c|c|c|c|c|}
\hline ST2 & ST3 & ST4 & ST5 & Carry out \\
\hline \hline Carry out & Point out & Point out & Point out & Go on \\
\hline Point out & Carry out & Carry out & Bring up up & Take on \\
\hline Bring up & Bring up & Bring up & Take on & Point out \\
\hline Bring about & Take on & Get away & Go on out \\
\hline Take on & Get away & Go on & & Carry out \\
\hline
\end{tabular}

mantic transparency is to infer the meaning of the whole phrase verb from the composition, and the metaphor is not to be inferred from the literal meaning of the constituent elements. Such as "walked out of the building He" and "walked out on his wife. He" are the two cases respectively. In this paper, the two forms of the phrase verb are also included in the study. A huge number of English phrasal verbs will combine all may be a particle of exhaustive combination of phrasal verbs constitute a is not realistic [10]. Johansson and Hofland list 20 adverbs of the verb with the verb, Quirk also proposed the 28 most suitable for the form of the phrase. On the basis of Biber will commonly use verb and the particle, through combination and screening, 31 high frequency verb phrases list and compare them in different styles in the corpus frequency of use. And Waibel retrieval LOCNESS and international learning English Corpus (the International Corpus of Learner English. Icle) after the number of Biber word phrasal verbs amplification to 72 . In this study, we use Waibel to analyze the 72 commonly used phrases.

According to the standard proposed by Liao and Zhang Bin, all verb phrases can be divided into two subgroups: se- mantic transparency and figurative meaning. Since the word verb is very common, we take the highest frequency in the two corpora. Such as "back" as a comeback for semantic transparency, as the "memories" or "criticism" is figurative, but senses of "return" in LOCNESS and CLEC use frequency highest so return to semantic transparency group. All of the phrase verbs are grouped in Table 5. Phrasal verb retrieval strategy is using wordsmith 3.0 software. In each sub corpus of 72 phrasal verb retrieval, particles and verbs interval is set to 1 to 5 words [11], it is necessary to consider verbs all participle form, search manual contextand and exclude non phrasal verbs combination; statistical phrasal verbs appear in each sub corpus frequency, standardized processing (frequency / sub corpus of total words).

\subsection{Results}

The frequency of the phrase verb in the CLEC each sub corpus is more than that in the LOCNESS (Overuse) [12], and the Underuse is less. (LOCNESS standard frequency CLEC in standardized frequency) frequency were calculated 


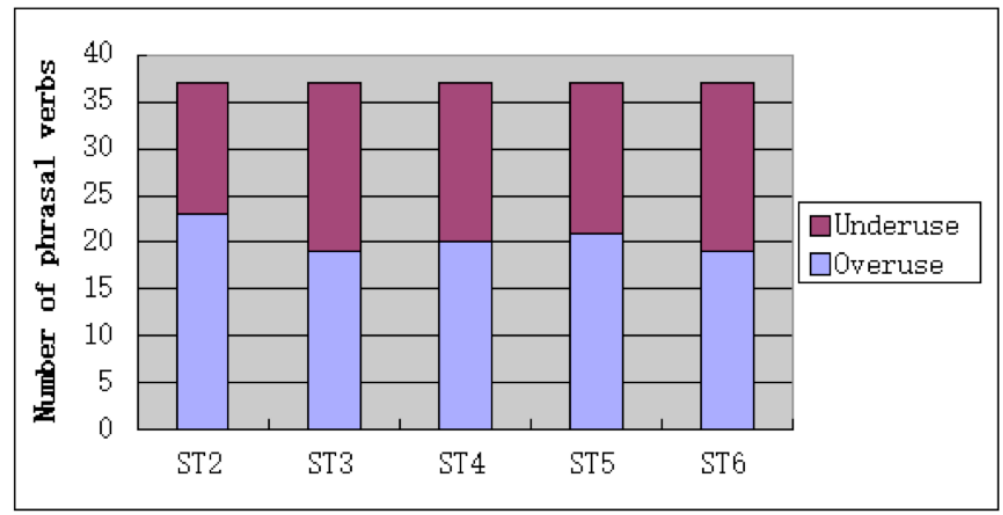

Fig. (1). The number of super words and the use of less words in 37 semantic transparent phrases.

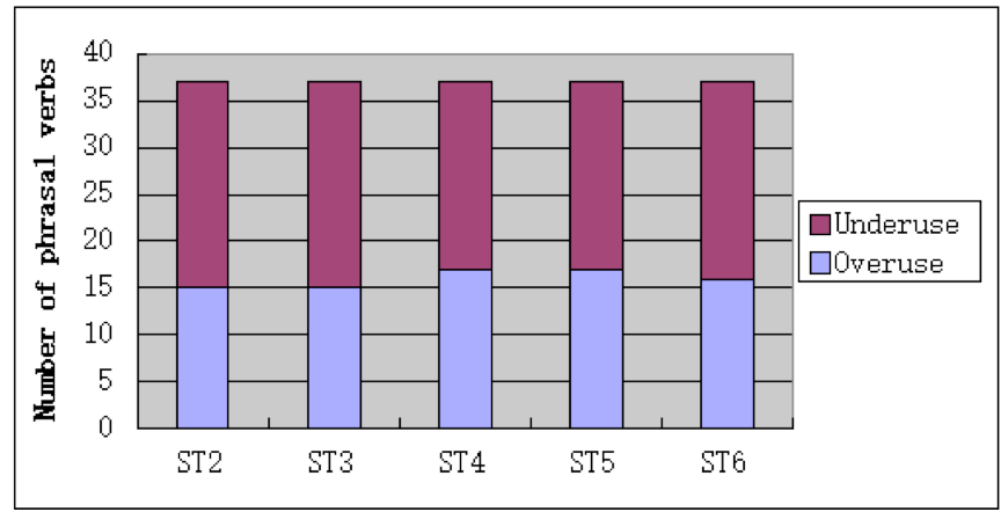

Fig. (2). The number distribution of super words and the use of less words in 35 metaphorical phrases.

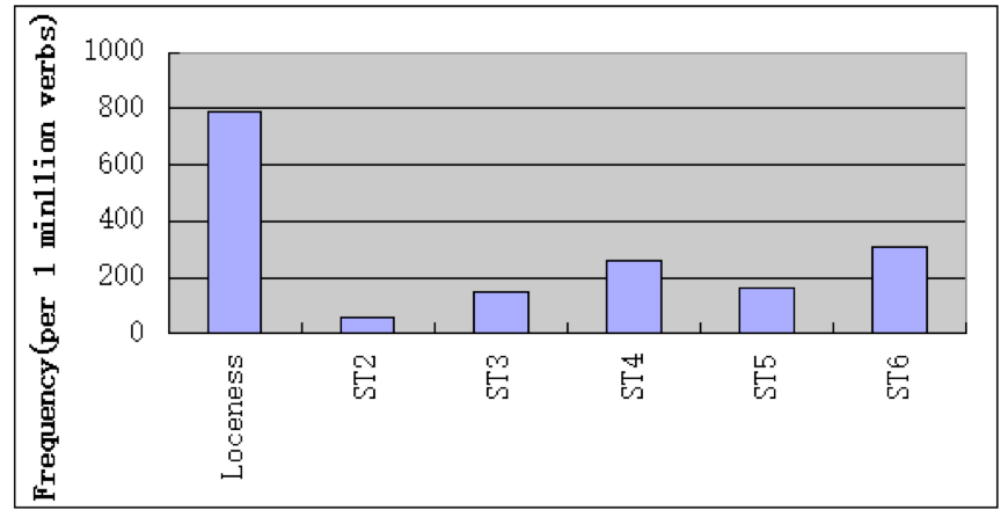

Fig. (3). The frequency of use of 29 little words in each corpus.

for each phrasal verb use or less use of super, and accordingly to words and less use of word order (Tables 6 and 7).

In the 37 semantic transparent phrase verb, the number of words and the use of the word is shown in Fig. (1).

In the 35 metaphorical phrase verb, the number of the super word and the use of the word is shown in Fig. (2).

In the 72 phrasal verbs, a total of 29 all sub corpus is rarely used phrasal verbs belong to, general use frequency as shown in Fig. (3), frequency by standardization is processed (frequency/sub corpus of total words).

\subsection{Discussion}

The study by the research methods of corpus linguistics, compared with 72 phrasal verbs in LOCNESS and CLEC frequency of Chinese English learners' acquisition of the phrasal verbs. After statistics, the differences of the 5 super used phrases are different. Among them, "go out" and "get up" are all levels of learners [13]. In each sub corpus, "go out" the vast majority are "out" using meanings, "get up" is "up" meaning use, such as: "... without her One day, my mother went out, I came back from school, but I..."....Sunday. Dec 3 Sunny Today I got up early First I went to...."'Go out" and" get up" the words in the various 
versions of the junior middle school or primary school English textbooks appear and the frequency is high, learners often in the initial stages of the learning of basic words repeated up to the memory of the most firmly. The initial usage of vocabulary has a profound effect on the English writing habits of the learners, so that the verbs in all levels of the students are very serious. In another study, we had interviewed junior high school students and asked respondents to without thinking talk get up sentences, the maximum sentence is "get up early in the morning". After the CLEC corpus analysis, in the English major and non-English major college students' compositions, the highest frequency of up get is early and earlier. Also, "up early in the morning get" sentence patterns are also very high [14]. And in locness cannot find such a combination and sentence patterns. This phenomenon may have a great relationship with the contents of the high school textbooks.

The advantage of corpus research is that all the materials are real writing material, and it is more objective to reflect the choice of words in normal writing process. Corpus based study of the phenomenon of over use or avoidance, is based on the probability theory, to some extent, to avoid the generation of bias, the results and inferences more reliable. The research results can be used to the use of each phrase verb, which can be used in the teaching process according to the research conclusion. Corpus research also has its shortcomings, the present English learning corpus size is smaller, text content is limited, in the present study, some phrasal verbs in many sub corpus, retrieval results of zero, which makes study of phrasal verbs with a very difficult, and also caused some degree of bias on the conclusions of this study [15]. In addition, the differences in the genre and the composition of the corpus also affect the credibility of the horizontal comparison among different corpora.

\section{CONCLUSION}

This study uses the corpus data to study the use of verb phrases in Chinese learners. Through the comparison of three levels, the study shows that the semantic features of the phrase verbs and the learning sequence have a greater impact on the use of the Chinese learners. In the oral expression of Chinese learners, the use of the phrase verb is lower. This discovery reveals that Chinese learners are a problem, that is, the spoken language is written. In order to make the Chinese English learners use the phrase verb more accurately, the teacher should emphasize the equivalence of the semantic equivalence between the phrase verb and the individual word in the teaching process. On the other hand, teachers should use the evidence from the corpus of native English speakers to inform the students of the different contexts in which the two types of words are used. In addition, the teacher can be used in the corpus of teaching, increasing the input of students to the real corpus. Let the students observe the different characteristics of the two types of verbs, and then the teacher will be summed up. Such students will have a clearer and thorough understanding of the use of these two types of verbs, thus reducing the use and misuse of the phenomenon.

\section{CONFLICT OF INTEREST}

The author confirms that this article content has no conflict of interest.

\section{ACKNOWLEDGEMENTS}

This work is supported National Social Science Fund Project: "study abroad" in the context of the development of Chinese college students' English productive skills and characteristics (Nos: 13CYY029), Research foundation of Shanghai Maritime University: a cognitive model of English and Chinese bilingual dictionary of lexical collocation information (Nos: 20120130).

\section{REFERENCES}

[1] M. Chen, "Overuse or underuse: A corpus study of English phrasal verb use by Chinese, British and American university students", International Journal of Corpus Linguistics, vol. 18, no. 3, pp. 418442, 2013.

[2] K.C. Bronshteyn and T. Gustafson, "The acquisition of phrasal verbs in L2 English: A literature review", Linguistic Portfolios, vol. 4, no. 1, p. 8, 2015.

[3] J. Huber, "Stefan Thim, 2012. Phrasal Verbs. The English Verb Particle Construction and its History. Topics in English Linguistics 78. Berlin/Boston: De Gruyter Mouton” Language Dynamics and Change, vol. 4, no. 2, pp. 301-306, 2014.

[4] D.W. Brown, and C.C. Palmer, "The phrasal verb in american english: using corpora to track down historical trends in particle distribution, register variation, and noun collocations", Studies in the History of the English Language VI: Evidence and Method in Histories of English, vol. 85, p. 71, 2015.

[5] L.J. Brinton, "Phrasal verbs: The English verb-particle construction and its history by Stefan Thim (review)", Language, vol. 89, no. 3, pp. 664-667, 2013.

[6] D. Liu, "The most frequently used English phrasal verbs in American and British English: A multicorpus examination", TESOL Quarterly, vol. 45, no. 4, pp. 661-688, 2011.

[7] Y. Oe and Y.S. Alam, "Picture-based e-learning of English phrasal verbs: A comparative study of the use of pictures and L1 glosses", International Journal of Humanities and Arts Computing, vol. 7(supplement), pp. 222-233, 2013.

[8] B. Cappelle, "Stefan Thim, Phrasal verbs: The English verbparticle construction and its history (Topics in English Linguistics 78)", Berlin and New York: De Gruyter Mouton, 2012. pp. xiv+ 302. ISBN978-3-11-025702-1. English Language and Linguistics, vol. 18 , no. 3 , pp. $572-586,2014$.

[9] A. Dillard, "Non-Native Speaker Attentional Capacity and the Processing of English Phrasal Verb Constructions", Doctoral dissertation, University of South Carolina, USA, 2014.

[10] M. Garnier, and N. Schmitt, "The PHaVE List: A pedagogical list of phrasal verbs and their most frequent meaning senses", Language Teaching Research, vol. 19, no. 6, pp. 645-666, 2015.

[11] P. Birjandi, S.M. Alavi and K.S. Najafi, "Effects of unenhanced, enhanced, and elaborated input on learning English phrasal verbs", International Journal of Research Studies in Language Learning, vol. 4, no. 1, pp. 43-59, 2014.

[12] M. Hilpert "Stefan Thim. Phrasal Verbs: The English Verb-Particle Construction and its History" Anglia, vol. 132, no. 2, pp. 374-378, 2014.

[13] M. Negishi, Y. Tono and Y. Fujita, "A validation study of the CEFR levels of phrasal verbs in the English vocabulary profile", English Profile Journal, vol. 3, p. e3, 2012. 
[14] W. Xiao-Hui, "A Study on the historical development of the English phrasal verb and the syntactic test", China Off Campus Education, vol. 12, p. 054, 2014.
[15] P.G. Thiruumeni, M. Kumar, V. Dhanalakshmi and K.P. Soman, "An approach to handle idioms and phrasal verbs in English-Tamil machine translation system", vol. 8, 10.5120/3139-4328, 2012.

Received: June 10, 2015

Revised: July 29, 2015

Accepted: August 15, 2015

(C) Yongchang Rong; Licensee Bentham Open.

This is an open access article licensed under the terms of the (https://creativecommons.org/licenses/by/4.0/legalcode), which permits unrestricted, noncommercial use, distribution and reproduction in any medium, provided the work is properly cited. 